\title{
A RAPID VALIDATED UNI-DIMENSIONAL DOUBLE DEVELOPMENT HPTLC-DENSITOMETRY METHOD FOR SIMULTANEOUS ESTIMATION OF METFORMIN HYDROCHLORIDE, GLICLAZIDE AND PIOGLITAZONE HYDROCHLORIDE
}

\author{
RAJESH VARADE1, HARSHA MISHRA ${ }^{1,2 *}$ \\ ${ }^{1}$ Pacific University, Udaipur, Rajasthan, India 313024, ${ }^{2} \mathrm{~K}$. J. Somaiya Institute of Engineering and Information Technology, Mumbai, Mh, \\ India 400022 \\ Email: harshamisra1@gmail.com
}

Received: 20 Dec 2018 Revised and Accepted: 17 May 2019

\begin{abstract}
Objective: To develop and validate a uni-dimensional double development high-performance thin layer chromatography (UDDD-HPTLC) for estimation of anti-diabetic medicine compromising of metformin (MET) gliclazide (GLZ) and pioglitazone hydrochloride (PIO).

Methods: The chromatographic separation of these drugs was carried out on precoated TLC plates silica gel 60F254by two mobile phases consisting of Ammonium Sulphate: Methanol: Acetonitrile: Water (4:3:2:1) for MET and PIO and Toluene: Ethyl Acetate: Formic Acid (6:4:0.5) for GLZ respectively for ideal separation and good resolution. The densitometric detection and quantification were carried out at $237 \mathrm{~nm}$ for MET and $200 \mathrm{~nm}$ for GLZ and PIO. The validation parameters were strictly followed as per the ICH guidelines.
\end{abstract}

Results: The linearity range was obtained at 3000-8000ng/spot, 360-960 ng/spot, 90-240 ng/spot for MET, GLZ and PIO with $\mathrm{r}^{2}$ value>0.999. The other parameters such as precision, reproducibility, robustness were efficiently obtained within the limits. The proposed method was successfully applied for simultaneous determination of MET, GLZ and PIO in the commercial formulation.

Conclusion: In simultaneous estimation, the different polarity of drugs makes it more cumbersome to develop and validate any chromatographic method. In the present study, a uni-dimensional double development high-performance thin layer chromatography (UDDD-HPTLC) for estimation of these drugs have been developed and validated to resolve the estimation problem. It is an effortless and speedy method which was developed and validated using ICH guidelines. The developed and validated method using ICH guidelines is effortless and speedy technique.

Keywords: HPTLC, Double-development, Metformin, Gliclazide, Pioglitazone, Validation, Simultaneous, ICH

(C) 2019 The Authors. Published by Innovare Academic Sciences Pvt Ltd. This is an open-access article under the CC BY license (http://creativecommons.org/licenses/by/4.0/) DOI: http://dx.doi.org/10.22159/ijpps.2019v11i7.31586

\section{INTRODUCTION}

Metformin (MET) is chemically, 1-carbamimidamido-N-N-dimethylmethanimidamide (fig. 1) [1]. It is an oral anti-diabetic drug from the biguanide class. It is the first-line drug for the treatment of type-2 diabetes, particularly in overweight and obese people and those with normal kidney function and evidences suggest it may be the best choice for the people with heart failure. The major action of MET is increasing glucose transport across the cell membrane in skeletal muscle [2].

Gliclazide (GLZ) is chemically N-(hexahydrocyclopenta(c) pyrrol-2(1H)-ylcarbamoyl)-4-methyl) benzene sulphonamide (fig. 2). Gliclazide is an oral hypoglycemic (anti-diabetic) and is classified as a sulphonylurea. It is used in type 2 diabetes mellitus that is a noninsulin dependent diabetes mellitus. GLZ was proven to protect human pancreatic beta cells from hyperglycemia-induced apoptosis. It was also shown to have an anti-atherogenic effect (preventing the accumulation of fat in arteries) in type 2 diabetes. GLZ selectively binds to sulphonylurea receptors (SUR-1) on the surface of the pancreatic beta-cells [3]

Pioglitazone hydrochloride (PIO) is $( \pm)-5-(\mathrm{p}-[2-(5-$-Ethyl-2-pyridyl) ethoxy]benzyl)-2,4-thiazolidinedione hydrochloride (fig. 3). Pioglitazone belongs thiazolidinedione group which is a class of oral anti-diabetic drugs that enhance target tissue insulin sensitivity. Pioglitazone has been shown to affect abnormal glucose and lipid metabolism associated with insulin resistance by enhancing insulin action on peripheral tissues [4].

It is observed through a literature review that many spectrophotometric and chromatographic methods have been reported for the estimation of single as well as combined formulations containing Metformin, Gliclazide and Pioglitazone hydrochloride [5-15].
MET has been simultaneously determined with PIO by spectrophotometric methods, [16, 17], by HPLC in the binary mixture [18-21], and with other components by HPLC [22-25]. GLZ has been simultaneously determined with MET by spectrophotometric methods, [26-28], by LC in dosage forms [29$33]$, and in human plasma [34, 35]. Spectrophotometric determinations have been reported for mixtures composed of more than two drugs [36-38]. Literature also reveals the use of the ionpairing technique [39-42], and micellar liquid chromatography [43], to develop a successful HPLC method for the determination of gliclazide and/or metformin.

Among different analytical tools TLC is one of the multi-applicative, quickest, accurate and robust method. However, the literature survey does not reveal any HPTLC method for simultaneous estimation of MET, GLZ and PIO in combined tablet dosage form. The reason for this can be the polarity difference among the three drugs. But, TLC application is so diverse that it offers various special development modes such, as multidimensional development, unidimensional multiple development (UMD), incremental multiple development (IMD), gradient multiple development (GMD), etc. [44] All these methods, improve the resolution of the components because of each consecutive development results in band reconcentration and thus, it enhances the efficiency of the separation $[44,45]$. In this current research work, we have applied the same principle and have successfully developed and validate UDDDHPTLC method for the simultaneous estimation of MET, GLZ and PIO.

Therefore, a simple and new UDDD-HPTLC method has been developed and validated for their estimation of MET, GLZ and PIO in bulk and combined tablet dosage form. UDDD-HPTLC techniques allow separation of compounds with a large difference in polarity. 
When the combined formulation have drugs with different polarity the chromatographic study like HPLC becomes costly, tedious and more time-consuming affair. Thus, in such case, HPTLC method with robust, easy detection and time-saving characteristics can be effectively employed.

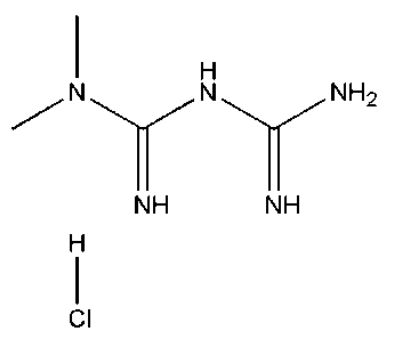

1,1-dimethylbiguanide hydrochloride

Fig. 1: Structure of metformin (MET)

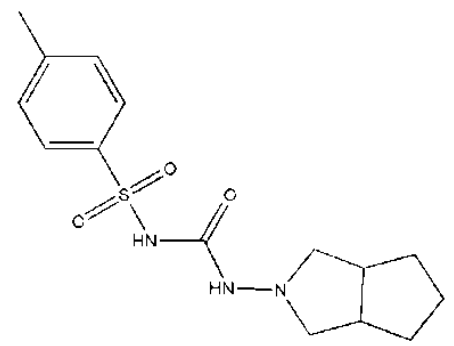

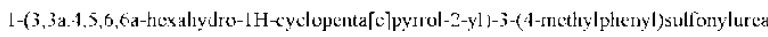

Fig. 2: Structure of gliclazide (GLZ)

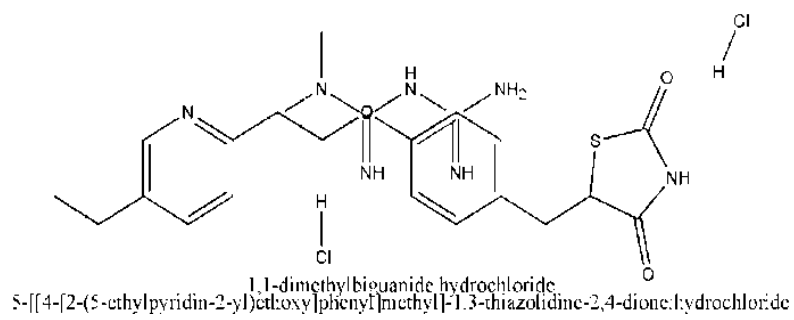

Fig. 3: Structure of pioglitazone hydrochloride (PIO)

\section{MATERIALS AND METHODS}

\section{Chemical and reagents}

MET, GLZ and PIO API procured as a gift sample from Ipca Laboratories Limited Mumbai. The marketed formulation (Glycinorm Total) with fixed dose combination tablets of the three compounds, (MET, GLZ, PIO) was purchased from retail pharmacy in Mumbai (Maharashtra, India). Other chemicals and reagents of analytical grade were purchased from Merck (India).

\section{Chromatographic conditions}

A CAMAG HPTLC system equipped with Linomat 5 autosampler, TLC scanner 3, and winCATS 1.2.2 software (CAMAG, Muttens, Switzerland) was employed. The slit dimension was kept at $5.00 \times$ $0.45 \mathrm{~mm}$, and $20 \mathrm{~mm} / \mathrm{sec}$ scanning speed was employed. Chromatography was performed on precoated silica gel 60 F254 TLC plates $(20 \times 10 \mathrm{~cm}$ ) (Merck, Darmstadt, Germany) using Ammonium Sulphate: Methanol: Acetonitrile: Water (4:3:2:1) for MET and PIO and Toluene: Ethyl Acetate: Formic Acid (6:4:0.5) for GLZ respectively as mobile phase. The band length $6 \mathrm{~mm}$ and distance between bands $15 \mathrm{~mm}$ were kept constant throughout the study. The application speed was $150 \mathrm{nl} / \mathrm{sec}$. Ascending development to a distance of $85 \mathrm{~mm}$ was performed on $20 \times 10 \mathrm{~cm}$ twin through the chamber (CAMAG). Densitometric scanning was achieved over a camag TLC scanner III operated using winCATS software (V 1.4.4. CAMAG). The source of radiation used was a UV Spectrophotometer, using spectral data the $\lambda$ max was determined for each compound.

\section{Preparation of solutions}

\section{Standard stock solution}

The standard stock solutions with a concentration of $1 \mathrm{mg} / \mathrm{ml}$ of the individual standard were prepared in methanol.

\section{Sample stock solution}

Twenty tablets were weighed and crushed to a fine powder. The quantity of powder equivalent to $500 \mathrm{mg}$ MET, $60 \mathrm{mg} \mathrm{GLZ}$ and $15 \mathrm{mg}$ PIO was weighed and transferred to a $100 \mathrm{ml}$ volumetric flask. The solution containing $5 \mathrm{mg} / \mathrm{ml}$ MET and $0.6 \mathrm{mg} / \mathrm{ml} \mathrm{GLZ} 0.15 \mathrm{mg} / \mathrm{ml}$ PIO. The solution was filtered through Whatmann filter paper number 41.

\section{Validation of the method}

\section{Linearity}

The standard stock solution with $1 \mathrm{mg} / \mathrm{ml}$ each MET and GLZ, PIO were prepared in methanol. Different volumes of each solution were applied to the HPTLC plate to deliver 3000-8000 ng of MET, 360-960 ng of GLZ, 90-240 ng of PIO per spot. Each concentration was analyzed in duplicate [46].

\section{Precision}

The precision of the developed method was evaluated by performing intra-day and inter-day precision. Intra-day precision was assessed based on triplicate of three different concentrations of MET (3000, 5000, 7000ng/spot), GLZ $(360,600,960 \mathrm{ng} / \mathrm{spot})$ and PIO $(90,150,240 \mathrm{ng} / \mathrm{spot})$. The inter-day precision of the method was verified by performing a similar method on different days under the same set of experimental conditions. The repeatability study of the same application and calculation of the peak area for the analyte was articulated in terms of the \% RSD [46].

\section{Accuracy}

The accuracy of the method was assessed by determination of recovery of the method at 3 different concentrations $(80 \%, 100 \%$ and $120 \%$ levels) by addition of known amounts of MET, GLZ and PIO. At each level, six determinations were performed to evaluate the accuracy studies. The results were recorded in the form of percent recovery and percent RSD of all three drugs [46].

\section{Limit of detection and limit of quantitation}

The detection limit of an individual analytical procedure is the lowest amount of analyte in a sample that can be detected but not necessarily quantitated as an exact value. The quantitation limit of an individual analytical procedure is the lowest amount of analyte in a sample that can be quantitatively determined with suitable precision and accuracy. In order to estimate the limit of detection (LOD) and limit of quantitation (LOQ), the signal to noise ratio $(\mathrm{S} / \mathrm{N}$ ) of 3 and 10 was determined for six to replicate determinations for each drug [46].

\section{Specificity}

The specificity of the method was by means of complete separation of pure drugs in the presence of other excipients normally present in the formulation. Peak purity of MET, GLZ and PIO was assessed by comparing their respective spectra at peak start (S), peak apex (M) and peak end (E) position of the spots [46].

\section{Robustness}

The robustness was studied by evaluating the effect of small but deliberate variations in the chromatographic conditions. Following the introduction of small changes in the mobile phase composition $( \pm 0.1 \mathrm{ml}$ for each component), the amount of mobile phase was varied over the range of $\pm 5 \%$. The time from spotting to chromatography and from chromatography to scanning was varied 
by+10 min. The effect of these changes on both the Rf values and peak areas was examined by calculating the \%RSD for each parameter [46].

\section{Analysis of tablet sample}

The validated method was used for the simultaneous quantitation of Metformin, Gliclazide and Pioglitazone hydrochloride in the tablet dosage form. Further, $5 \mathrm{ml}$ of stock solution of the sample was diluted with $10 \mathrm{ml}$ of methanol to get the concentration of $2.5 \mathrm{mg} / \mathrm{ml} \mathrm{MET}, 0.3$ $\mathrm{mg} / \mathrm{ml} \mathrm{GLZ}$ and $0.75 \mathrm{mg} / \mathrm{ml}$ PIO. The analysis was repeated in triplicate [46].

\section{RESULTS AND DISCUSSION}

Chromatographic separation of the standard solution of MET, GLZ and was performed. Briefly, the spot of the standard solution was applied on TLC plates. The TLC plates were developed by linear ascending development by using various solvents such as acetone, benzene, chloroform, ethyl acetate, methanol and toluene. The experimental condition for the HPTLC method such as mobile phase composition and the wavelength of detection was optimized to provide accurate, precise and reproducible, compact, flat bands for simultaneous determination of MET, GLZ and PIO.

During the stage of method development different mobile phases were tried and the mobile phase comprising of Ammonium Sulphate: Methanol: Acetonitrile: Water (4:3:2:1) for MET and PIO and Toluene: Ethyl Acetate: Formic Acid (6:4:0.5) for GLZ respectively were confirmed. The spectral data revealed the $\lambda$ max for MET at $237 \mathrm{~nm}$ and for GLZ and PIO at $200 \mathrm{~nm}$. The chromatographic conditions confirmed for the analysis gave wellresolved peaks for each standard. (fig. 4 and fig. 5).

A good linear relationship was obtained over the concentration ranges 200-1000, 360-960 and $90-240 \mathrm{ng} / \mathrm{spot}$ for MET, GLZ and PIO respectively. The linear regression data showed a regression coefficient of 0.9993 for MET (fig. 6), 0.9987 for GlZ (fig. 7) and 0.9993 for PIO (fig. 8). The LOD with signal/noise ratio was found to be 357.7, 150.24 and $61.745 \mathrm{ng} / \mathrm{spot}$ for MET, GLZ, and PIO respectively. The LOQ with signal/noise ratio was found to be 1084.0, 455.27 and $187.105 \mathrm{ng} /$ spot for MET, GLZ, and PIO respectively.

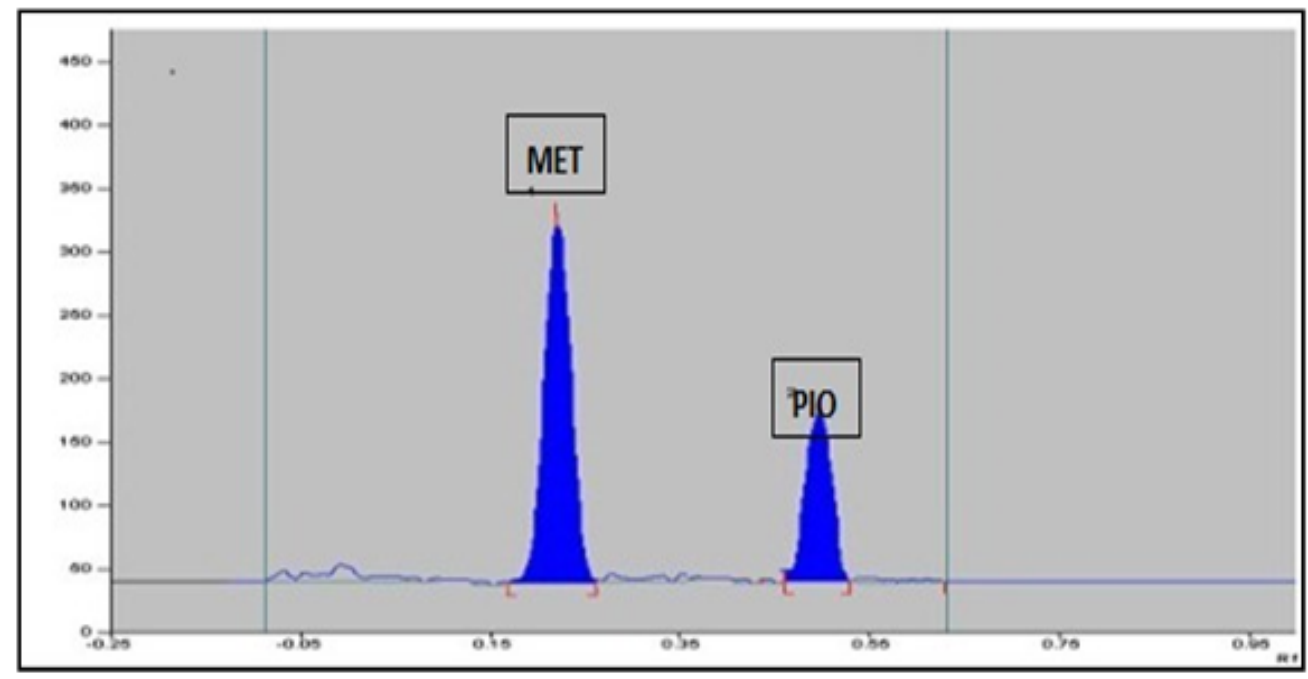

Fig. 4: HPTLC profile of MET and PIO

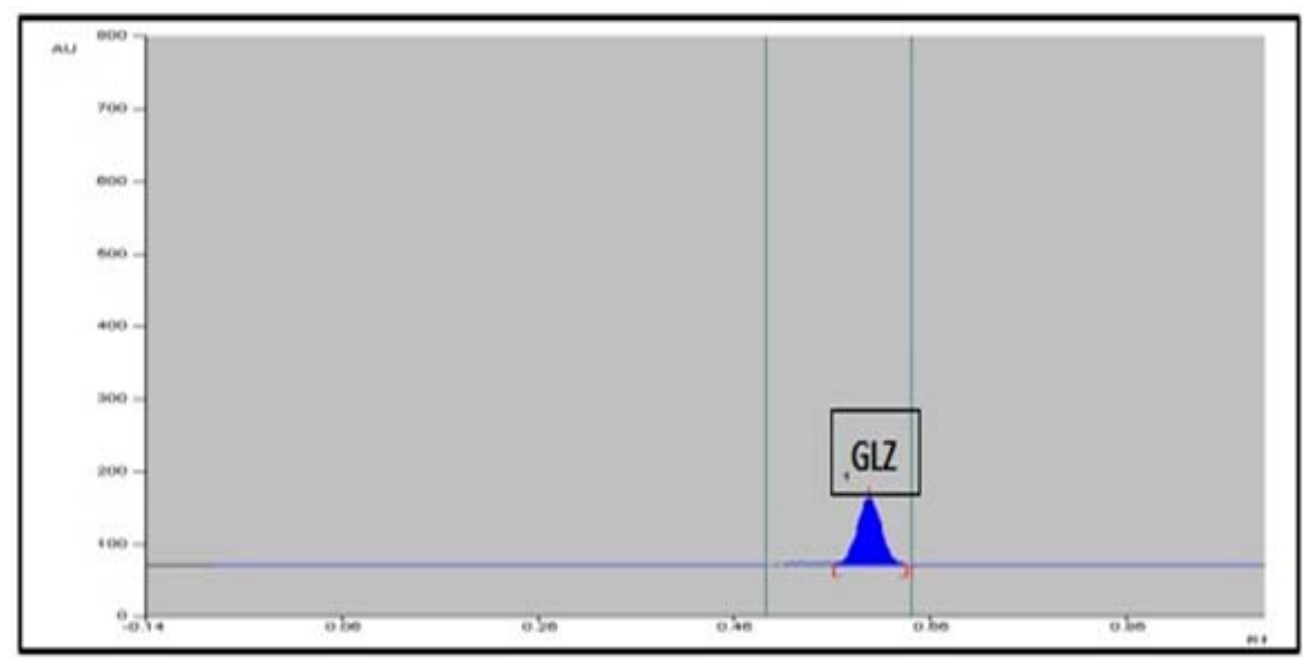

Fig. 5: HPTLC profile of GLZ

The intraday and inter-day precision showed excellent \% RSD less than $2 \%$ (table 1, 2 and 3). The recovery was 101.6, 101.4 and $100.6 \%$ for MET, $99.8,100.4$ and $100.6 \%$ for GLZ and 100.6, 99.1,
$101.7 \%$ for PIO at $80 \%, 100 \%$ and $120 \%$ levels (table 4 ). The robustness parameter was also successfully carried and the results were satisfying and within the limits. (table 5.1, 5.2, 5.3) 


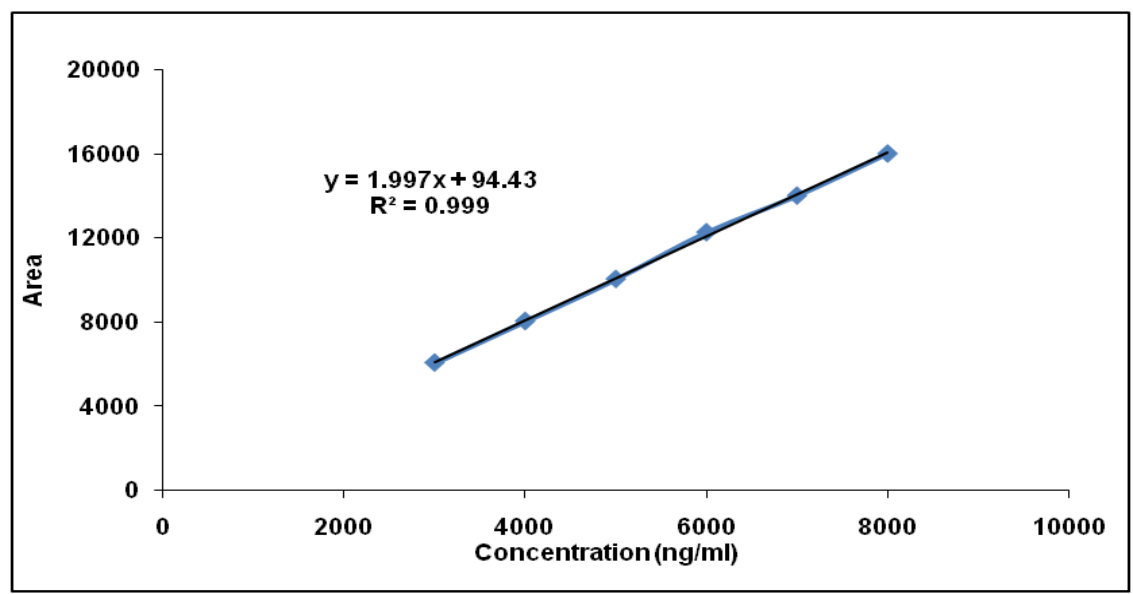

Fig. 6: Linearity graph of MET

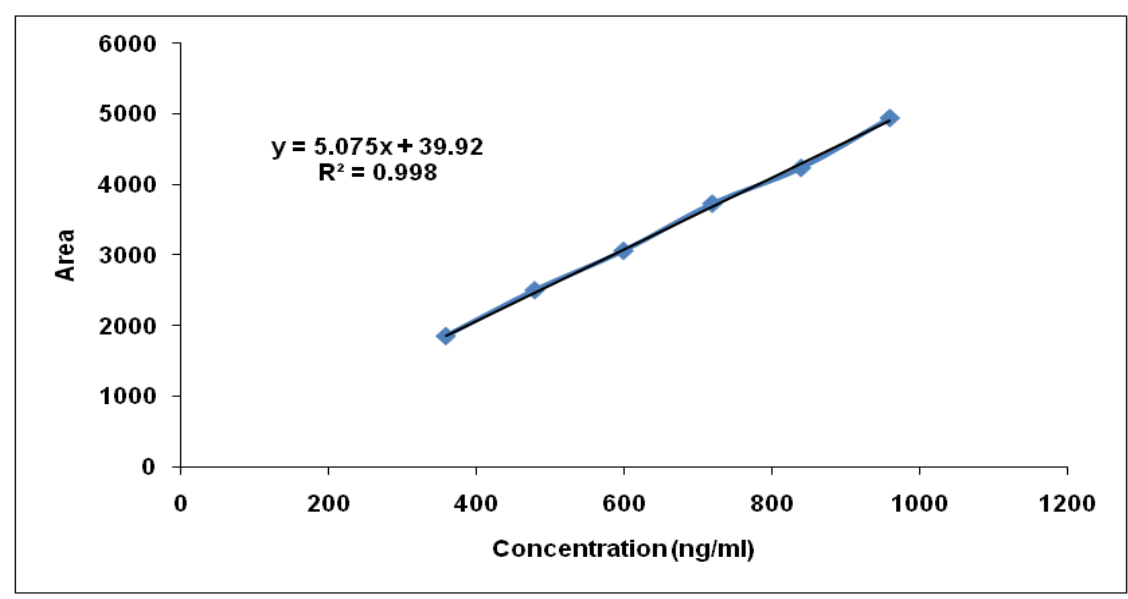

Fig. 6: Linearity graph of GLZ

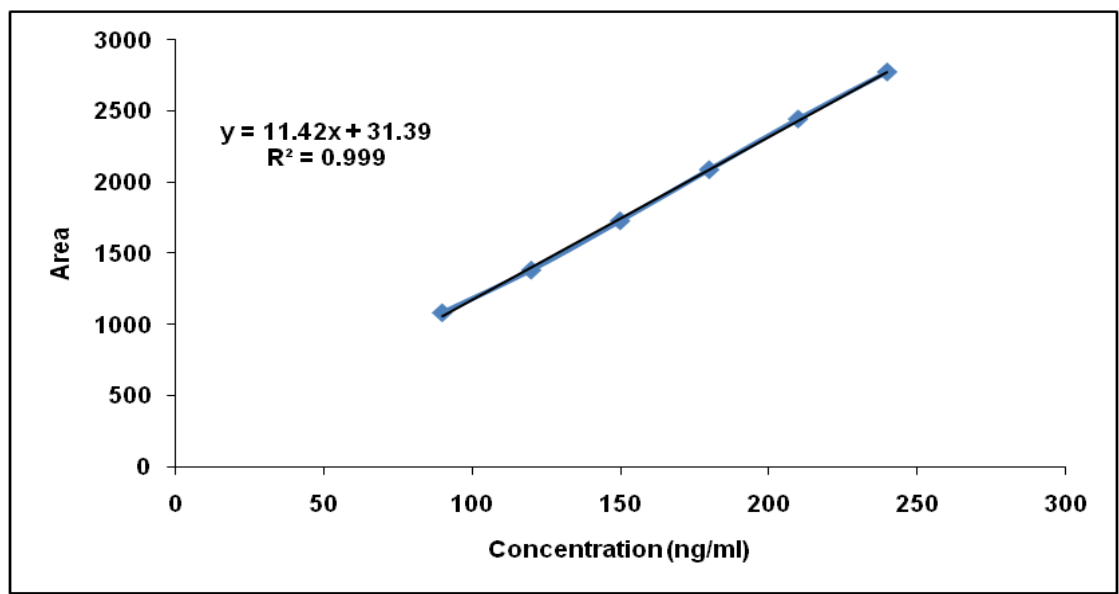

Fig. 6: Linearity graph of PIO

Table 1: Evaluation of intra-day and inter-day precision of MET

\begin{tabular}{|c|c|c|c|c|}
\hline \multirow[t]{2}{*}{ MET taken (ng/spot) } & \multicolumn{2}{|l|}{ Intra-day precision } & \multicolumn{2}{|l|}{ Inter-day precision } \\
\hline & MET found(ng/spot) mean \pm SD & $\%$ RSD & MET found (ng/spot) mean \pm SD & \% RSD \\
\hline 3000 & $3080.4 \pm 50.52$ & 1.64 & $3037.8 \pm 26.13$ & 0.86 \\
\hline 5000 & $5134.8 \pm 91.91$ & 1.79 & $5220.7 \pm 81.96$ & 1.57 \\
\hline 7000 & $7119.7 \pm 128.87$ & 1.81 & $7356.3 \pm 100.78$ & 1.37 \\
\hline
\end{tabular}

$\mathrm{SD}=$ Standard deviation, $\mathrm{RSD}=$ relative standard deviation 
Table 2: Evaluation of intra-day and inter-day precision of GLZ

\begin{tabular}{llll}
\hline GLZ taken (ng/spot) & Intra-day precision & \multicolumn{1}{c}{ Inter-day precision } \\
\cline { 2 - 4 } & GLZ found(ng/spot) mean+SD & \% RSD & GLZ found (ng/spot) mean \pm SD \\
\hline 360 & $357.3 \pm 4.93$ & 1.38 & $355.6 \pm 3.13$ \\
600 & $598.6 \pm 6.46$ & 1.08 & $597.1 \pm 5.37$ \\
960 & $969.4 \pm 13.77$ & 1.42 & $965.6 \pm 15.16$ \\
\hline
\end{tabular}

$\mathrm{SD}=$ Standard deviation, $\mathrm{RSD}=$ Relative Standard deviation

Table 3: Evaluation of intra-day and inter-day precision of PIO

\begin{tabular}{llll}
\hline \multirow{2}{*}{ PIO taken (ng/spot) } & Intra-day precision & \multicolumn{1}{c}{ Inter-day precision } \\
\cline { 2 - 4 } & PIO found (ng/spot) mean \pm SD & \% RSD & PIO found (ng/spot) mean \pm SD \\
\hline 90 & $97.6 \pm 1.82$ & 1.86 & $97.3 \pm 170.28$ \\
150 & $149.7 \pm 2.77$ & 1.85 & $150.0 \pm 1.38$ \\
240 & $235.4 \pm 4.26$ & 1.81 & $234.8 \pm 3.38$ \\
\hline
\end{tabular}

$\mathrm{SD}=$ Standard deviation, $\mathrm{RSD}=$ Relative Standard deviation

Table 4: Recovery data of MET, GLZ and PIO

\begin{tabular}{|c|c|c|c|c|c|c|c|c|c|}
\hline \multirow[t]{2}{*}{ Level (\%) } & \multicolumn{3}{|c|}{ Amount added (ng) } & \multicolumn{3}{|c|}{ Amount found (ng) mean \pm SD } & \multicolumn{3}{|c|}{ \% Recovery } \\
\hline & MET & GLZ & PIO & MET & GLZ & PIO & MET & GLZ & PIO \\
\hline 80 & 4800 & 580 & 150 & $4868 \pm 16.99$ & $582 \pm 10.23$ & $149 \pm 1.29$ & 101.4 & 100.4 & 99.1 \\
\hline 100 & 6000 & 720 & 180 & $6094 \pm 41.63$ & $718 \pm 5.06$ & $181 \pm 2.39$ & 101.6 & 99.8 & 100.6 \\
\hline 120 & 7200 & 860 & 220 & $7245 \pm 84.02$ & $865 \pm 12.65$ & $224 \pm 1.15$ & 100.4 & 100.6 & 101.7 \\
\hline
\end{tabular}

$\mathrm{SD}=$ Standard deviation, $\mathrm{RSD}=$ Relative Standard deviation

Table 5.1: Robustness study for developed study of metformin

\begin{tabular}{|c|c|c|c|c|}
\hline Parameter & MET & & & \\
\hline Concentration in ng/spot & 3000 & 5000 & 7000 & $\% \mathrm{RSD}$ \\
\hline Mobile phase composition $( \pm 0.1 \mathrm{ml})$ mean \pm SD & $6425.33 \pm 99.51$ & $10425.33 \pm 100.50$ & $14300.33 \pm 77.72$ & 1.02 \\
\hline Amount of mobile phase $( \pm 5 \%)$ mean \pm SD & $6315 \pm 95.69$ & $10319.3 \pm 73.42$ & $14342.7 \pm 167.73$ & 1.13 \\
\hline Time from spotting to chromatography ( $\pm 10 \mathrm{~min})$ mean \pm SD & $6328 \pm 72.08$ & $10526.33 \pm 204.26$ & $14461.67 \pm 204.26$ & 1.63 \\
\hline Time from chromatography to scanning ( $\pm 10 \mathrm{~min})$ mean \pm SD & $6863.67 \pm 115.94$ & $10718.33 \pm 170.10$ & $14692.67 \pm 159.10$ & 1.45 \\
\hline
\end{tabular}

$\mathrm{SD}=$ Standard deviation, $\mathrm{RSD}=$ Relative Standard deviation

Table 5.2: Robustness study for developed study of Gliclazide

\begin{tabular}{|c|c|c|c|c|}
\hline Parameter & GLZ & & & \\
\hline Concentration in ng/spot & 360 & 600 & 960 & \%RSD \\
\hline Mobile phase composition $( \pm 0.1 \mathrm{ml})$ mean \pm SD & $1878.67 \pm 16.50$ & $3085.33 \pm 36.64$ & $4759.33 \pm 85.01$ & 1.28 \\
\hline Amount of mobile phase $( \pm 5 \%)$ mean \pm SD & $1845.67 \pm 23.01$ & $3083.00 \pm 35.79$ & $4937.67 \pm 35.10$ & 1.04 \\
\hline Time from spotting to chromatography ( $\pm 10 \mathrm{~min})$ mean \pm SD & $1855.33 \pm 12.34$ & $3079.67 \pm 41.05$ & $4892.3 \pm 14.2$ & 0.76 \\
\hline Time from chromatography to scanning ( $\pm 10 \mathrm{~min})$ mean \pm SD & $1848.00 \pm 3.61$ & $3045.67 \pm 45.65$ & $4881.33 \pm 62.07$ & 0.99 \\
\hline
\end{tabular}

$\mathrm{SD}=$ Standard deviation, $\mathrm{RSD}=$ Relative Standard deviation

Table 5.3: Robustness study for developed study of Pioglitazone hydrochloride

\begin{tabular}{|c|c|c|c|c|}
\hline Parameter & PIO & & & \\
\hline Concentration in ng/spot & 90 & 150 & 240 & $\%$ RSD \\
\hline Mobile phase composition $( \pm 0.1 \mathrm{ml})$ mean \pm SD & $1126.67 \pm 14.503$ & $1725.67 \pm 3.512$ & $2741.33 \pm 25.813$ & 0.81 \\
\hline Amount of mobile phase $( \pm 5 \%)$ mean \pm SD & $1129 \pm 14.526$ & $1747 \pm 28.919$ & $2739 \pm 36.497$ & 1.42 \\
\hline Time from spotting to chromatography $( \pm 10 \mathrm{~min})$ mean \pm SD & $1117.67 \pm 4.163$ & $1729 \pm 11.14$ & $2706.33 \pm 77.37$ & 1.29 \\
\hline Time from chromatography to scanning $( \pm 10 \mathrm{~min})$ mean \pm SD & $1116.33 \pm 7.51$ & $1735.33 \pm 15.31$ & $2717 \pm 37.47$ & 0.98 \\
\hline
\end{tabular}

$\mathrm{SD}=$ Standard deviation, $\mathrm{RSD}=$ Relative Standard deviation

This developed and validated the method for the simultaneous analysis of MET, GLZ and PIO in pharmaceutical preparations was successfully employed. The assay results of tablet dosage form are shown in table 6 .
Assay results show excellent label claim of 99.4\% for Metformin, 100.1\% for Gliclazide and $99.7 \%$ for Pioglitazone hydrochloride. Final, optimum characteristics and validation parameters are summarized in table 7.

Table 6: Assay results of tablet dosage form

\begin{tabular}{|c|c|c|c|c|c|c|c|c|c|}
\hline \multirow{2}{*}{$\begin{array}{l}\text { Formulation } \\
\text { Glycinorm Total }\end{array}$} & \multicolumn{3}{|c|}{ Actual added (mg) } & \multicolumn{3}{|c|}{ Amount found $\pm(\mathrm{mg})$} & \multicolumn{3}{|c|}{$\%$ drug found \pm SD } \\
\hline & MET & GLZ & PIO & MET & GLZ & PIO & MET & GLZ & PIO \\
\hline & 500 & 60 & 15 & 498 & 58.8 & 14.2 & $99.4 \pm 0.15$ & $100.1 \pm 0.09$ & $99.7 \pm 0.08$ \\
\hline
\end{tabular}

$\mathrm{SD}=$ Standard deviation, $\mathrm{RSD}=$ Relative Standard deviation 
Table 7: Optical characteristic and validation parameter of MET, GLZ and PIO

\begin{tabular}{|c|c|c|c|}
\hline Parameter & MET & GLZ & PIO \\
\hline Wavelength & 237 & 200 & 200 \\
\hline Linearity range (ng/Spot) & $3000-8000$ & $360-960$ & $90-240$ \\
\hline Correlation co-efficient $(\mathrm{r} 2)$ mean \pm SD & $0.9993 \pm 0.0019$ & $0.9987 \pm 0.0006$ & $0.9993 \pm 0.0012$ \\
\hline Retention factor & 0.22 & 0.60 & 0.48 \\
\hline Intercept & 94.43 & 39.92 & 31.39 \\
\hline Slope of regression & 2.00 & 5.03 & 11.43 \\
\hline Limit of detection (LOD, ng/spot) & 179.06 & 29.59 & 5.40 \\
\hline Limit of quantitation (LOQ, ng/spot) & 542.61 & 89.65 & 13.60 \\
\hline Assay $(\%)$ mean \pm SD & $99.4 \pm 0.15$ & $100.1 \pm 0.09$ & $99.7 \pm 0.08$ \\
\hline
\end{tabular}

$\mathrm{SD}=$ Standard deviation, $\mathrm{RSD}=$ Relative Standard deviation

\section{CONCLUSION}

The developed UDDD-HPTLC method is new, less time consuming, precise, accurate and robust. The double development feature in TLC method enables estimation of any kind of compounds simultaneously. It is concluded that the developed method offers several advantages such as rapid, cost-effective, simple mobile phase, easy sample preparation steps and improved sensitivity made it reliable and easily reproducible in quality control set-up providing all the parameters are followed accurately for its intended use. The proposed UDDD-HPTLC method is novel, less expensive, simpler, rapid, and more flexible than HPLC. This method allows simultaneous estimation of all API on one single TLC plate with a single application and thus, it can be employed for routine quality control analysis.

\section{AUTHORS CONTRIBUTIONS}

All the authors have contributed equally

\section{CONFLICT OF INTERESTS}

Declared none

\section{REFERENCES}

1. The Indian Pharmacopoeia. 4th ed. Vol. I. New Delhi: The controller of publications; 1996. p. 469.

2. Tripathi KD. Essential of medical pharmacology. 5th Edn. Jaypee Brothers Medical publisher. New Delhi; 2003. p. 254-73.

3. Satoskar R, Rege N, Bhandarkar S. Pharmacology and pharmacotherapeutics. Elsevier Health Sciences; 2015.

4. Lippincott Williams and Wilkins, Wilson and Gisvolds textbook, organic medicinal and pharmaceutical chemistry. 11th edition; 2002. p. 668-70.

5. USP 36 NF31, U. S. Pharmacopoeia National Formulary 31Official monographs/Pioglitazone and Glimepiride; 2013. p. 4807, 3730.

6. Goswami L, Mukhopadhyay S, Durgapal S. Simultaneous estimation of metformin and pioglitazone by ultraviolet spectrophotometry. Indian J Pharm Sci 2010;72:508-10.

7. Sujana K, Swathi G, Rani M, Bhanu Prasad, M Saheethi Reddy, Sujana K. Simultaneous estimation of pioglitazone hydrochloride and metformin hydrochloride using UV spectroscopic method. J Biomed Sci Res 2010;2:110-5.

8. Havele OS, Havele SS. Simultaneous determination of atorvastatin calcium and pioglitazone hydrochloride in its multicomponent dosage forms by UV spectrophotometry. Int J Pharm Pharm Sci 2011;1:75-9.

9. Basniwal P, Srivastava P, Jain D. Spectrophotometric estimation of pioglitazone hydrochloride in the tablet dosage form. Asian J Pharm 2008;2:225-7.

10. Rathod SD, Patil PM, Jadhav SB, Chaudhari PD. UV spectrophotometric simultaneous determination of metformin hydrochloride and pioglitazone hydrochloride in the combined dosage form. Am J Phys Anthropol 2012;2:5-9.

11. Jain D, Jain S, Jain D, Maulik Amin. Simultaneous estimation of metformin hydrochloride, pioglitazone hydrochloride, and glimepiride by RP-HPLC in tablet formulation. JCS 2008;46:501-4.

12. Mahatma ATO, Joshi M. A validated RP-HPLC method for simultaneous determination of metformin $\mathrm{HCl}$, pioglitazone
$\mathrm{HCl}$ and glimepiride in pharmaceutical formulation. J Pharm Res Opin 2014;3:82-96.

13. P Raja, Thejaswini JC, Gurupadayya BM, K Sowjanya. Determination and validation of metformin, glimepiride, and pioglitazone using atorvastatin as an Internal standard in bulk drug and pharmaceutical dosage form. Int J Air-Cond Refrig 2011;18:61-8.

14. Patel JR, Suhagia BN, Patel MM. Simultaneous estimation of glimepiride and pioglitazone in bulk and in pharmaceutical formulation by HPTLC method. Asian J Chem 2006;18:2873-8.

15. Jiladia M, Pandya S, Viidyasagar G. A simple and sensitive HPTLC method for estimation of pioglitazone In bulk and tablet dosage forms. Asian J Res Chem 2009;2:207-9.

16. Sujana K, Swathi Rani G, Bhanu Prasad M, Reddy MS. Simultaneous estimation of pioglitazone hydrochloride and metformin hydrochloride using UV spectroscopic method. J Biomed Sci Res 2010;2:110-5.

17. Goswami L, Mukhopadhyay S, Durgapal S. Simultaneous estimation of metformin and pioglitazone by ultraviolet spectrophotometry. Indian J Pharm Sci 2010;72:508-10.

18. Jajow Swapna, Chandaka Madhu, Mallepelli Srivani, Sumalatha M, Nehalatha Y. Analytical method development and method validation for the simultaneous estimation of metformin hydrochloride and pioglitazone hydrochloride in tablet dosage form by RP-HPLC. Asian J Pharm Anal 2012;2:85-9.

19. Lakshmi KS, Rajesh T, Sharma S. Simultaneous determination of metformin and pioglitazone by reversed phase HPLC in pharmaceutical dosage forms. Int J Pharm Pharm Sci 2009;1:162-6.

20. Sahoo PK, Sharma R, Chaturvedi SC. Simultaneous estimation of metformin hydrochloride and pioglitazone hydrochloride by RPHPLC method from combined tablet dosage form. Indian J Pharm Sci 2008;70:383-6.

21. Srinivas P, Venkataramana K, Mangamma K. Simultaneous determination of metformin and pioglitazone tablets in pharmaceutical dosage form by RP-HPLC method. Int JPCBS 2012;2:104-9.

22. Jain D, Jain S, Jain D, Amin M. Simultaneous estimation of metformin hydrochloride, pioglitazone hydrochloride, and glimepiride by RP-HPLC in tablet formulation. J Chromatogr Sci 2008;46:501-4.

23. Freddy HH, Vairal DL. Simultaneous estimation of metformin hydrochloride, rosiglitazone and pioglitazone hydrochloride in the tablets dosage form. Int J Appl Biol Pharm 2010;7:1326-33.

24. Sultana N, Saeed Arayne M, Nighat S, Siddiqui FA, Hussain A. Development and validation of new assay method for the simultaneous analysis of diltiazem, metformin, pioglitazone and rosiglitazone by RP-HPLC and its applications in pharmaceuticals and human serum. J Chromatogr Sci 2011;49:774-9.

25. Sankar ASK, Vetrichelvan TV, Venkappaya D. Simultaneous quantification and validation of five antidiabetic and hyperlipidemic drugs using isocratic RP-HPLC and its application to the marketed formulations. J Pharm Res 2012;5:1217-20.

26. Ketan PD, Parthika AN, Agrawal YK. Development and validation of a spectrophotometric method for simultaneous estimation of gliclazide and metformin hydrochloride in bulk and tablet dosage form by simultaneous equation method. Int J Pharm Sci Res 2011;2:1559-63. 
27. Dhabale PN, Seervi CR. Simultaneous UV spectrophotometric method for estimation of gliclazide and metformine hydrochloride in tablet dosage form. J Chem Tech Res 2010;2:813-7.

28. Radhika B, Rahul B, Mahendra KS, Vipin S, Bhat K. UVspectrophotometric-assisted chemometric methods for the simultaneous determination of metformin hydrochloride and gliclazide in pharmaceutical formulations. Pharm Anal Acta 2012;3:1-5.

29. El-Wasseef DR. Simultaneous determination of metformin, nateglinide and gliclazide in pharmaceutical preparations using micellar liquid chromatography. Int J Biomed Sci 2012;8:14451.

30. Fatema K, Md Zakiur R, Tasnuva H, Mohammad Abdul KA, Reza MS. Development and validation of a simple method for simultaneous estimation of metformin hydrochloride and gliclazide in tablets by using reversed-phase high-performance liquid chromatography Dhaka University. J Pharm Sci 2010;9:83-9.

31. Vasudevan M, Ravi J, Ravisankar S, Suresh B. ION-pair liquid chromatography technique for the estimation of metformin in its multicomponent dosage forms. J Pharm Biomed Anal 2001;25:77-84.

32. Elkady, Ehab, El-Zaher, Asmaa, Elwy, Hanan Mohamed, et al. Validated liquid chromatographic method for simultaneous determination of metformin, pioglitazone, sitagliptin, repaglinide, glibenclamide and gliclazide-application for counterfeit drug analysis. J Anal Bioanal Tech 2015;2155-9872.

33. Anusha Akula, Prajwala N, Sandhya M, Rao DUM. Development and validation of RP-HPLC method for simultaneous estimation of metformin hydrochloride and gliclazide in bulk and combined doasage form. Int J Pharm Pharm Sci 2013;5:511-7.

34. Maria Cristina R, Mihaela I, Lavinia H, Elena I, Valentina A. Validation of a HPLC method for the simultaneous analysis of metformin and gliclazide in human plasma. Farmacia 2009;57:728-35.

35. Zhong GP, Bi HC, Zhou S, Chen X, Huang M. Simultaneous determination of metformin and gliclazide in human plasma by liquid chromatography-tandem mass spectrometry: application to a bioequivalence study of two formulations in healthy volunteers. J Mass Spectrom 2005;40:1462-71.
36. Chaturvedi PK, Sharma R. Simultaneous spectrophotometric estimation and validation of three component tablet formulation containing pioglitazone hydrochloride, metformin hydrochloride and glibenclamide. Anal Lett 2008;41:2133-42.

37. Narsimha Rao D, Shanmugasundaram P, Vaishnav H. Method development and validated of simultaneous estimation of metformin hydrochloride, pioglitazone hydrochloride and glibenclamide in pure and tablet dosage form by the spectrophotometric multi-component method. Int J Chemtech Res 2011;3:2011-17.

38. Dhole SM, Pramod BK, Amnerkar ND. UV spectrophotometric absorption correction method for the simultaneous estimation of pioglitazone $\mathrm{HCl}$, metformin $\mathrm{HCl}$ and glibenclamide in the multicomponent formulation. Int $\mathrm{J}$ Anal Bioanal Chem 2013;3:18-22.

39. Ranetti MC, Ionescu M, Hinescu L, Ionica E, Anuta V, Ranetti AE. Validation of a HPLC method for the simultaneous analysis of metformin and gliclazide in human plasma. Farmacia 2009;57:728-35.

40. Rao BU, Nikalje AP. Determination of gliclazide in a tablet dosage form in the presence of metformin hydrochloride by ion pair reversed-phase liquid chromatographic technique. Afr J Pharm Pharmacol 2011;5:1331-7.

41. S Abu Ruz, J Millership, J Mc Elnay. The development and validation of liquid chromatography method for the simultaneous determination of metformin and glipizide, gliclazide, glibenclamide or glimperide in plasma. J Chromatogr B 2005;817:277-86.

42. T Eva, D Leonard, B Gezim. Ion-pair HPLC method for the quantification of metformin in human urine. J Appl Bioanal 2016;2:16-24.

43. DR El-Wasseef. Simultaneous determination of metformin, nateglinide and gliclazide in pharmaceutical preparations using micellar liquid chromatography. Int J Biomed Sci 2012;8:144-51.

44. Szabady B. The different modes of development in planar chromatography. Springer Budapest; 2001. p. 88.

45. Poole CF, Poole SK, Fernando WPN. Multidimensional and multimodal thin layer chromatography: the pathway to the future. J Planar Chromatogr 1989;332:6.

46. IPM Biotech ICH Topic Q 2 B. Validation of Analytical Procedures: Methodology; 1996. 